\title{
PENGARUH CUSTOMER ENGAGEMENT DAN E-SERVICE QUALITY TERHADAP ONLINE REPURCHASE INTENTION DENGAN CUSTOMER SATISFACTION SEBAGAI VARIABEL INTERVENING PADA MARKETPLACE SHOPEE
}

\author{
Alfi Nurul Hikmah, Sulis Riptiono \\ Sekolah Tinggi Ilmu Ekonomi Putra Bangsa
}

Email: alfinurulhikmah739@gmail.com

\begin{abstract}
Abstrak
Penelitian ini dilakukan berdasarkan fenomena, dan didukung jurnal yang ada, sehingga peneliti tertarik melakukan penelitian tentang pengaruh customer engagement dan e-service quality terhadap online repurchase intention dengan customer satisfaction sebagai variabel intervening. Tujuan penelitian ini adalah menganalisis dan menjelaskan pengaruh antara variabel independen, variabel intervening dan variabel dependen.

Populasi penelitian ini yaitu mahasiswa STIE Putra Bangsa Kebumen pengunjung marketplace Shopee. Sampel dalam penelitian ini sebanyak 100 orang. Teknik pengambilan sampel yang digunakan adalah accidental sampling. Metode pengumpulan data dengan kuesioner. Sikap responden diukur dengan skala likert 4 tingkatan dan data yang diperoleh diolah dengan analisis SPSS (Statistical Product and Service Solution) for windows versi 24.0. Analisis data menggunakan analisis deskriptif, dan analisis statistik (analisis jalur).

Hasil penelitian menunjukkan bahwa terdapat pengaruh signifikan antara variabel customer engagement terhadap customer satisfaction, selanjutnya e-service quality berpengaruh signifikan terhadap customer satisfaction, customer engagement berpengaruh signifikan terhadap online repurchase intention, e-service quality berpengaruh signifikan terhadap online repurchase intention, serta customer satisfaction berpengaruh signifikan terhadap online repurchase intention.
\end{abstract}

Kata Kunci: Customer Engagement, E-Service Quality, Customer Satisfaction, Online Repurchase Intention.

\begin{abstract}
This Research is based on phenomena and supported by existing journals, so researchers are interested in conducting research on the effect of customer engagement and e-service quality on online repurchase intention with customer satisfaction as an intervening variable. The purpose of this research is to analyze and explain the influence between independent variables, intervening variables and dependent variables.

The population of this study is STIE Putra Bangsa Kebumen students Shopee marketplace visitors. Samples in this study were 100 people. This sampling technique used was accidental sampling. Methods of collecting data with a questionnaire. Respondents' attitudes were measured by a 4 likert scale and the obtained was processed by SPSS analysis(Statistical Product and Service Solution) for windows versi 24.0. Data analysis used descriptive analysis and statistical analysis (path analysis).

The results showed that there was a significan effect between the variable customer engagement on customer satisfaction, then e-service quality had a significant effect on customer satisfaction, customer engagement had a significant effect on online repurchase intention, e-service quality had a significant effect on online repurchase intention, and customer satisfaction had a significant effect on online repurchase intention.
\end{abstract}

Keywords : Customer Engagement, E-Service Quality, Customer satisfaction, Online Repurchase Intention. 


\section{Pengaruh Customer Engagement dan E-Service Quality Terhadap Online Repurchase Intention dengan Customer Satisfaction sebagai Variabel Intervening}

\section{PENDAHULUAN}

Asosiasi Penyelenggara Jasa Internet Indonesia (APJII) menyatakan pada tahun 2017 jumlah pengguna Internet mencapai 143,26 juta jiwa dibandingkan tahun sebelumnya yang hanya mencapai 132,7 juta jiwa, dari total populasi di Indonesia dengan jumlah penduduk 262 juta jiwa. Jumlah tersebut menimbulkan sebuah peluang khusus bagi pengusaha dan institusi sosial untuk dapat mencapai pangsa pasar dari pengguna internet dan mempengaruhi mereka untuk melakukan proses pertukaran informasi pada kegiatan bisnis berbasiskan media elektronik atau disebut $e$ commerce (Chaffey dalam Amelia, 2018). Ecommerce adalah kegiatan melakukan transaksi bisnis secara online melalui media internet dan perangkat-perangkat yang terintegrasi dengan internet (Laudon et al 2012).

Saat ini di Indonesia, belanja secara online telah menjadi pilihan banyak pihak untuk memperoleh barang. Pertumbuhan e-commerce yang terus meningkat di Indonesia membuat marketplace Shopee ikut meramaikan industri ini. Marketplace Shopee merupakan platform belanja berbasis online yang menyediakan beragam macam produk penjualan mulai dari elektronik, perlengkapan rumah tangga, pakaian, aksesoris hingga fashion. Marketplace Shopee saat ini berhasil menduduki peringkat pertama sebagai aplikasi yang paling banyak di download baik melalui App Store maupun Google Play Store. Hal ini membuktikan bahwa banyaknya pengguna aplikasi Shopee di Indonesia.

Berdasarkan hasil wawancara dan observasi awal yang dilakukan penelitian pada empat puluh mahasiswa STIE Putra Bangsa Kebumen yang pernah melakukan pembelian pada aplikasi belanja online Shopee, tiga puluh dari mereka menyatakan puas. Mereka merasa puas dan senang dengan gratis ongkir dan layanan yang telah diberikan Shopee, serta senang dengan game shopee, seperti: goyang shopee, kuis shopee, dan goyang hujan emas. Tiga puluh responden tersebut juga mengatakan bahwa mereka tidak hanya melakukan pembelian di marketplace Shopee sebanyak satu kali, namun berulang kali sesuka hati mereka. Ada beberapa alasan atau faktor yang menyebabkan mahasiswa STIE Putra Bangsa Kebumen melakukan pembelian di marketplace Shopee, mereka memberikan alasan yang berbeda-beda dalam niat pembelian ulang (repurchase intention) pada marketplace Shopee.

\begin{tabular}{|c|c|c|c|}
\hline No & $\begin{array}{l}\text { Jawaban } \\
\text { Responden }\end{array}$ & $\begin{array}{l}\text { Jumlah } \\
\text { Respon } \\
\text { den }\end{array}$ & Variabel \\
\hline 1. & 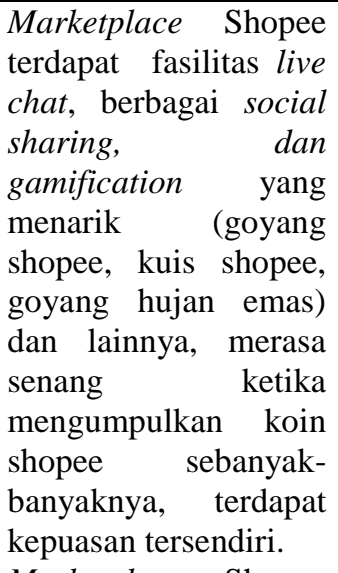 & to & $\begin{array}{c}\text { Customer } \\
\text { engagement }\end{array}$ \\
\hline 2. & $\begin{array}{lr}\text { Marketplace } & \text { Shopee } \\
\text { memberikan } & \\
\text { pelayanan } & \text { yang } \\
\text { memuaskan. } & \\
\end{array}$ & 19 & $\begin{array}{c}\text { E-service } \\
\text { quality }\end{array}$ \\
\hline & Jumlah & 30 & $\begin{array}{c}\text { Online } \\
\text { Repurchase } \\
\text { Intention }\end{array}$ \\
\hline
\end{tabular}

Faktor yang Mempengaruhi Niat Beli Ulang Terhadap Marketplace Shopee Pada Mahasiswa STIE Putra Bangsa Kebumen

Sumber:Hasil wawancara dan observasi, 2018

Berdasarkan hasil miniriset diatas dapat diketahui bahwa yang menjadi faktor yang mempengaruhi niat pembelian ulang mahasiswa STIE Putra Bangsa Kebumen pada marketplace Shopee yaitu keterikatan konsumen (customer engagement) dan kualitas layanan elektronik ( $e$ service quality). Kedua faktor tersebut diyakini menjadi faktor yang dominan dalam menentukan niat beli ulang online (online repurchase intention) pada marketplace Shopee.

Repurchase intention pada dasarnya merupakan perilaku pelanggan dimana mereka merespon secara positif terhadap e-service quality suatu perusahaan dan berniat untuk melakukan kunjungan kembali dan 


\section{Pengaruh Customer Engagement dan E-Service Quality Terhadap Online Repurchase Intention dengan Customer Satisfaction sebagai Variabel Intervening}

mengkonsumsi produk perusahaan tersebut (Cronin dalam Dian dan Rusfian 2013).

Customer engagement adalah segala usaha untuk melibatkan customer di dalam interaksi emosional antara perusahaan dengan customernya (Vivek dalam Ahmed dan Ghadha, 2017). Shopee dalam menciptakan konsumen yang engage adalah dengan cara melibatkan konsumen melalui game shopee agar mereka merasa senang dan berantusias ketika melakukan belanja online melalui aplikasi Shopee. Adanya fasilitas live chat, serta media social sharing agar tercipta hubungan yang engage antara konsumen dengan perusahaan, terciptanya komunikasi yang lebih intens agar konsumen mudah memperoleh informasi yang rinci mengenai apapun yang ingin mereka ketahui saat berbelanja pada marketplace Shopee.

Boone dan Kurtz (dalam Rokhmat dan Aqim, 2017), kepuasan konsumen (customer satisfaction) adalah "The ability of good or service to meet or exceed buyers needs and expectation." Konsumen akan merasa puas terhadap layanan yang diberikan oleh perusahaan apabila layanan tersebut mampu memenuhi kebutuhan dan harapan konsumen, tetapi seandainya, layanan yang diberikan tidak dapat memenuhi kebutuhan dan harapan konsumen, maka akan menimbulkan ketidakpuasan bagi konsumen tersebut.

Berdasarkan observasi yang peneliti lakukan kepada mahasiswa STIE Putra Bangsa Kebumen yang pernah melakukan pembelian pada marketplace Shopee, terdapat beberapa pelanggan yang meresa kecewa dengan pelayanan yang telah diberikan Shopee, ada juga pelanggan yang menerima barang tidak sesuai dengan pesanan, bahkan pengembalian uang yang tidak di proses oleh penjual, serta respon live chat yang lambat (slow respond) dalam melayani pelanggan. Namun terdapat juga pelanggan yang memiliki pengalaman yang baik, seperti senang dengan gratis ongkir, senang dengan adanya Shopee Pay yang mempermudah proses pembayaran, serta adanya garansi 7 hari untuk pengembalian barang yang tidak sesuai. Oleh karena itu, penelitian ini diperlukan untuk menganalisis kualitas layanan dan keterikatan konsumen yang diberikan oleh Shopee apakah mempengaruhi kepuasan konsumen, dan mampu mendorong customer untuk berniat melakukan pembelian ulang pada marketplace Shopee. Hasil dari penelitian ini diharapkan dapat membantu Shopee untuk meningkatkan kualitas layanan dan keterikatan pelanggan sesuai dengan hasil penelitian agar pelanggan tetap senantiasa melakukan pembelian pada marketplace Shopee.

Berdasarkan latar belakang diatas maka penulis tertarik untuk melakukan penelitian yang berjudul "Pengaruh Customer Engagement dan E- service Quality terhadap Online Repurchase Intention dengan Customer Satisfaction sebagai variabel intervening pada Marketplace Shopee (Studi pada Mahasiswa STIE Putra Bangsa Kebumen)”.

Tujuan Penelitian

1. Untuk mengetahui dan menganalisis variabel customer engagement dan pengaruhnya terhadap customer satisfaction pada mahasiswa STIE Putra Bangsa Kebumen.

2. Untuk mengetahui dan menganalisis variabel $e$ service quality dan pengaruhnya terhadap customer satisfaction pada mahasiswa STIE Putra Bangsa Kebumen.

3. Untuk mengetahui dan menganalisis variabel customer engagement dan pengaruhnya terhadap online repurchase intention pada mahasiswa STIE Putra Bangsa Kebumen.

4. Untuk mengetahui dan menganaisis variabel $e$ service quality dan pengaruhnya terhadap online repurchase intention pada mahasiswa STIE Putra Bangsa Kebumen.

5. Untuk mengetahui dan menganalisis variabel customer satisfaction dan pengaruhnya terhadap online repurchase intention pada mahasiswa STIE Putra Bangsa Kebumen.

\section{KAJIAN TEORI}

\section{Online Repurchase Intention}

Repurchase intention pada dasarnya merupakan perilaku pelanggan dimana mereka merespon secara positif terhadap e-service quality suatu perusahaan dan berniat untuk melakukan kunjungan kembali dan mengkonsumsi produk perusahaan tersebut (Cronin, 2000 dalam Dian dan Rusfian, 2013).

Indikator online repurchase intention menurut (Ferdinand, 2002) dalam jurnal (Saidani dan Arifin, 2012) yaitu : (1) Niat transaksional (2) Niat referensial (3) Niat preferensial (4) Niat eksploratif.

\section{Customer Satisfaction}

Heiler et al, (2003) dalam Dian dan Rusfian, (2013) mendefinisikan customer satisfaction sebagai keseluruhan perasaan senang dan puas yang dirasakan oleh konsumen, yang dihasilkan dari kemampuan untuk memenuhi keinginan, harapan dan 


\section{Pengaruh Customer Engagement dan E-Service Quality Terhadap Online Repurchase Intention dengan Customer Satisfaction sebagai Variabel Intervening}

kebutuhan konsumen sehubungan dengan jasa yang diberikan oleh perusahaan.

Indikator Customer Satisfaction menurut Anderson dan Srinivasan, (2003) yaitu sebagai berikut: (1) Pengalaman berbelanja yang diberikan suatu perusahaan e-commerce lebih tinggi dari ekspektasi pelaggan (2) Pelanggan puas dengan pengalaman berbelanja disuatu perusahaan e-comerce (3) Pelanggan tidak tertarik mencari alternative perusahaan $e$-commerce

\section{E-Service Quality}

Santos (2003) dalam Dian dan Rusfian (2013) mendefinisikan $e$-service quality sebagai penilaian dan evaluasi secara menyeluruh atas kualitas pengantaran layanan kepada konsumen didalam pasar virtual.

Indikator e-service quality Menurut Parasuraman, (2005) dalam jurnal Taufan et al (2016) ,ada tujuh indikator yang dapat diguakan sebagai pengukuran $e$ service quality adalah sebagai berikut: (1) Efficiency (2) Fulfillment (3) Reliability (4) Privacy(5) Responsiveness (6) Compensation (7) Contact.

\section{Customer Engagement}

The Marketing Science Institute (MSI, 2010) berpendapat bahwa customer engagement sebagai manifestasi perilaku pelanggan terhadap merek (perusahaan) diluar aktivitas pembelian memiliki arti yaitu perwujudan perilaku konsumen terhadap merek di luar aktivitas transaksi atau pembelian yang dihasilkan dari motivasi individu pelanggan, seperti word of mouth, rekomendasi, interaksi antar konsumen, menulis review, blogging dan aktivias lain yang sejenis.

Indikator Customer Engagement menurut So, King, \& Sparks (2014) dalam Rahmawati (2015) yaitu: (1) Enthusiams (2) Attention (3) Absorption (4) Interaction (5) Identification.

\section{Model Empiris}

Berdasarkan landasan teori yang telah dibahas, maka dapat disusun suatu model empiris yang digambarkan sebagai berikut:

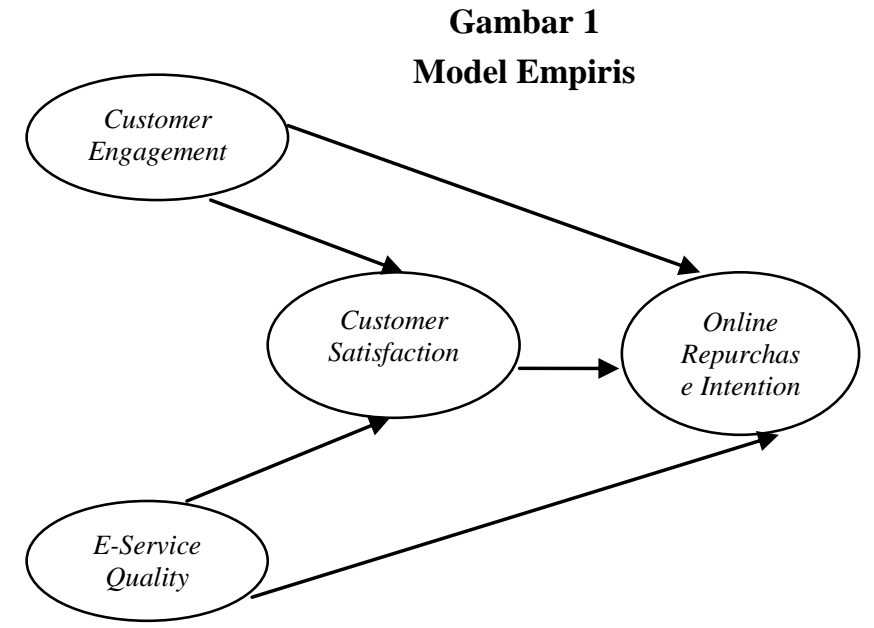

H1 : Terdapat pengaruh customer engagement terhadap customer satisfaction pada mahasiswa STIE Putra Bangsa Kebumen.

H2 : Terdapat pengaruh e-service quality terhadap customer satisfaction pada mahasiswa STIE Putra Bangsa Kebumen.

H3 : Terdapat pengaruh customer engagement terhadap online repurchase intention pada mahasiswa STIE Putra Bangsa Kebumen.

H4 : Terdapat pengaruh e-service quality terhadap online repurchase intention pada mahasiswa STIE Putra Bangsa Kebumen.

H5 : Terdapat pengaruh customer satisfaction terhadap online repurchase intention pada mahasiswa STIE Putra Bangsa Kebumen.

\section{METODE}

Penelitian ini dilakukan pada mahasiswa STIE Putra Bangsa yang pernah melakukan pembelian pada marketplace Shopee. Pengambilan sampel menggunakan teknik non probability sampling yaitu accidental sampling dengan jumlah responden sebanyak 100 orang. Pengumpulan data menggunakan kuesioner dengan skala likert, dengan masing-masing kesioner mengenai online repurchase intention 4 item pertanyaan, kuesioner customer satisfaction 3 item pertanyaan, kuesioner $e$ service quality 8 item pertanyaan, kuesioner customer engagement 5 item pertanyaan.

Teknik pengumpulan data yang dilakukan dengann cara : (1) menyebar kesioner secara online kepada mahasiswa STIE Putra Bangsa; (2) wawancara; (3) studi pustaka. Instrumen dalam penelitian ini dilakukan dengan menggunakan kesioner yang ditunjukkan untuk memperoleh jawaban dari responden. Alat bantu pengolahan data menggunakan SPSS for windows versi 24.0. Teknik analisis data dilakukan dengan dua cara yaitu analisis deskriptif dan analisis statistika. Analisis data secara statistika meliputi: (1) uji validitas dan uji reliabilitas; (2) uji asumsi klasik; (3) uji hipotesis; (4) analisis korelasi; (5) analisis jalur. 


\section{HASIL DAN PEMBAHASAN}

\section{Uji Validitas}

Menentukan $r_{\text {tabel }}$ (Gozali, 2009) dengan rumus df $=\mathrm{n}-2$

Keterangan:

$\mathrm{df}=$ degree of freedom

$\mathrm{n}=$ sampel

Dengan level of significance $95 \%$ maka dasar analisisnya (Gozali, 2009):

a. Apabila $r_{\text {hitung }}>r_{\text {tabel }}$ dengan tingkat signifikansi $<0,05$ berarti item tersebut valid.

b. Apabila $r_{\text {hitung }}<r_{\text {tabel }}$ dengan tingkat signifikansi $>0,05$ berarti item tersebut tidak valid.

Tabel 2

Hasil Uji Validitas Customer Engagement

\begin{tabular}{ccccc}
\hline Butir & $\mathrm{r}_{\text {hitung }}$ & $\mathrm{r}_{\text {tabel }}$ & Signifikansi & Ket \\
\hline X1.1 & 0,511 & 0,197 & 0,000 & Valid \\
X1.2 & 0,721 & 0,197 & 0,000 & Valid \\
X1.3 & 0,834 & 0,197 & 0,000 & Valid \\
X1.4 & 0,750 & 0,197 & 0,000 & Valid \\
X1.5 & 0,675 & 0,197 & 0,000 & Valid \\
\hline
\end{tabular}

Tabel 3

Hasil Uji Validitas E-Service Quality

\begin{tabular}{ccccc}
\hline Butir & $\mathrm{r}_{\text {hitung }}$ & $\mathrm{r}_{\text {tabel }}$ & Signifikansi & Ket \\
\hline X2.1 & 0,637 & 0,197 & 0,000 & Valid \\
X2.2 & 0,647 & 0,197 & 0,000 & Valid \\
X2.3 & 0,643 & 0,197 & 0,000 & Valid \\
X2.4 & 0,701 & 0,197 & 0,000 & Valid \\
X2.5 & 0,666 & 0,197 & 0,000 & Valid \\
X2.6 & 0,609 & 0,197 & 0,000 & Valid \\
X2.7 & 0,611 & 0,197 & 0,000 & Valid \\
X2.8 & 0,686 & 0,197 & 0,000 & Valid \\
\hline
\end{tabular}

Tabel 4

Hasil Uji Validitas Customer Satisfaction

\begin{tabular}{ccccc}
\hline Butir & $\mathrm{r}_{\text {hitung }}$ & $\mathrm{r}_{\text {tabel }}$ & Signifikansi & Ket \\
\hline Y1.1 & 0,806 & 0,197 & 0,000 & Valid \\
Y1.2 & 0,808 & 0,197 & 0,000 & Valid \\
Y1.3 & 0,769 & 0,197 & 0,000 & Valid \\
\hline
\end{tabular}

Tabel 5

Hasil Uji Validitas Online Repurchase Intention

\begin{tabular}{|c|c|c|c|c|}
\hline Butir & $r_{\text {hitung }}$ & $r_{\text {tabel }}$ & Signifikansi & Ket \\
\hline Y2.1 & 0,738 & 0,197 & 0,000 & Valid \\
\hline Y 2.2 & 0,823 & 0,197 & 0,000 & Valid \\
\hline Y 2.3 & 0,770 & 0,197 & 0,000 & Valid \\
\hline Y2.4 & 0,774 & 0,197 & 0,000 & Valid \\
\hline
\end{tabular}
semua instrument Customer Engagement, EService Quality, Customer Satisfaction, dan Online Repurchase Intention dinyatakan valid karena $r_{\text {hitung }}>r_{\text {tabel }}(0,197)$, dengan tingkat signifikansi sebesar $0,000<0,05$ sehingga semua item yang dipakai dinyatakan valid atau sah.

\section{Uji Reliabilitas}

Uji reliability butir dilakukan dengan ketentuan jika Cronbach's Alpha $>\mathrm{r}_{\text {kritis }}(0,60)$ sehingga dapat disimpulkan bahwa semua instrumen dalam penelitian dinyatakan reliable dan sebaliknya.

Tabel IV-6

Hasil Uji Reliabilitas

\begin{tabular}{llll}
\hline Variabel & $\mathrm{r}_{\text {kritis }}$ & $\begin{array}{l}\text { Cronbac } \\
\text { h's Alpha }\end{array}$ & Keterangan \\
\hline $\mathrm{X} 1$ & 0,60 & 0,740 & Reliabel \\
$\mathrm{X} 2$ & 0,60 & 0,803 & Reliabel \\
$\mathrm{X} 3$ & 0,60 & 0,693 & Reliabel \\
$\mathrm{X} 4$ & 0,60 & 0,775 & Reliabel \\
\hline
\end{tabular}

Berdasarkan tabel diatas, hasil analisis dapat dijelaskan bahwa seluruh variabel yang dipakai dalam penelitian ini dinyatakan reliable (andal) karena Cronbach's Alpha > $\mathrm{r}_{\text {kritis }}(0,60)$. 
Uji Asumsi Klasik

Uji Multikolonieritas

Tabel 7

Hasil Uji Multikolonieritas Substruktural 1

\begin{tabular}{lcc}
\hline \multirow{2}{*}{ Model } & \multicolumn{2}{c}{ Collinearity Statisics } \\
\cline { 2 - 3 } & Tolerance & VIF \\
\hline $\begin{array}{l}\text { Customer } \\
\text { Engagement }\end{array}$ & 0,506 & 1,977 \\
$\begin{array}{l}\text { E-Service } \\
\text { Quality }\end{array}$ & 0,517 & 1,936 \\
$\begin{array}{l}\text { Customer } \\
\text { Satisfaction }\end{array}$ & 0,488 & 2,047 \\
\hline
\end{tabular}

Tabel 8

Hasil Uji Multikolonieritas

Substruktural 2

Berdasarkan tabel diatas, dapat diketahui bahwa nilai tolerance diatas 0,10 dan VIF diatas 10, sehingga model regresi tidak

\begin{tabular}{lll}
\hline \multirow{2}{*}{ Model } & \multicolumn{2}{c}{ Collinearity Statisics } \\
\cline { 2 - 3 } & Tolerance & VIF \\
\hline $\begin{array}{l}\text { Customer } \\
\text { Engagement }\end{array}$ & 0,612 & 1,633 \\
$\begin{array}{l}\text { E-Service } \\
\text { Quality }\end{array}$ & 0,612 & 1,633 \\
\hline
\end{tabular}

terjadi multikolonieritas.

\section{Uji Heteroskedastisitas}

Gambar 2. Uji Heteroskedastisitas Sub struktural 1

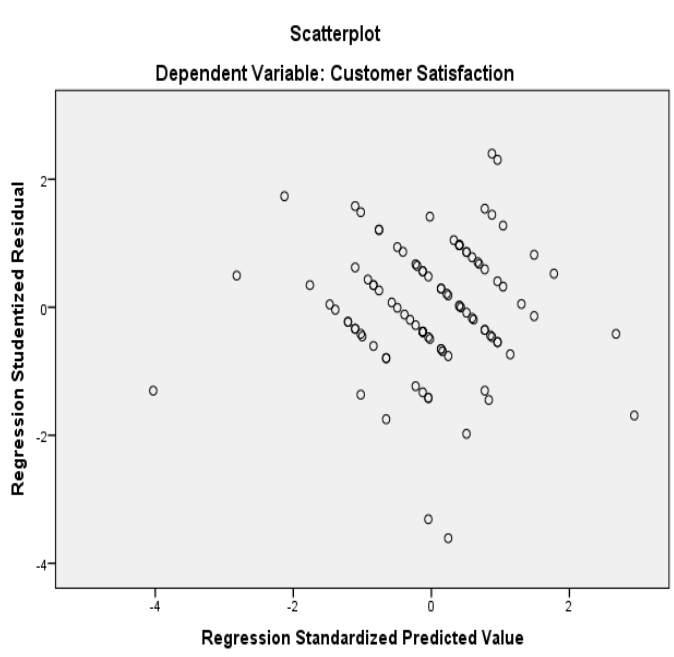

Gambar 3. Uji Heteroskedastisitas

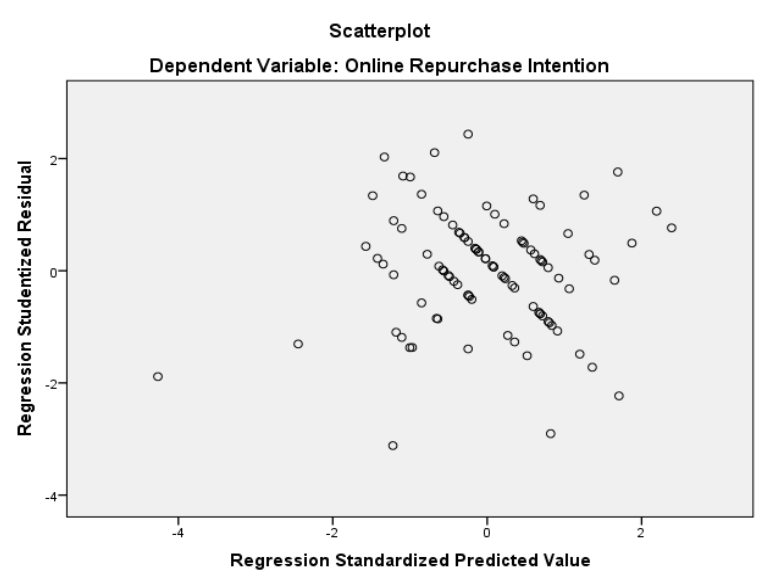

Substruktural 2

Berdasarkan gambar diatas menunjukkan bahwa tidak ada pola tertentu seperti titiktitik yang membentuk suatu pola tertentu yang jelas, sehingga dapat disimpulkan model regresi pada penelitian ini tidak terjadi heteroskedastisitas.

\section{Uji Normalitas}

\section{Gambar 4.Uji Normalitas Substruktural 1}

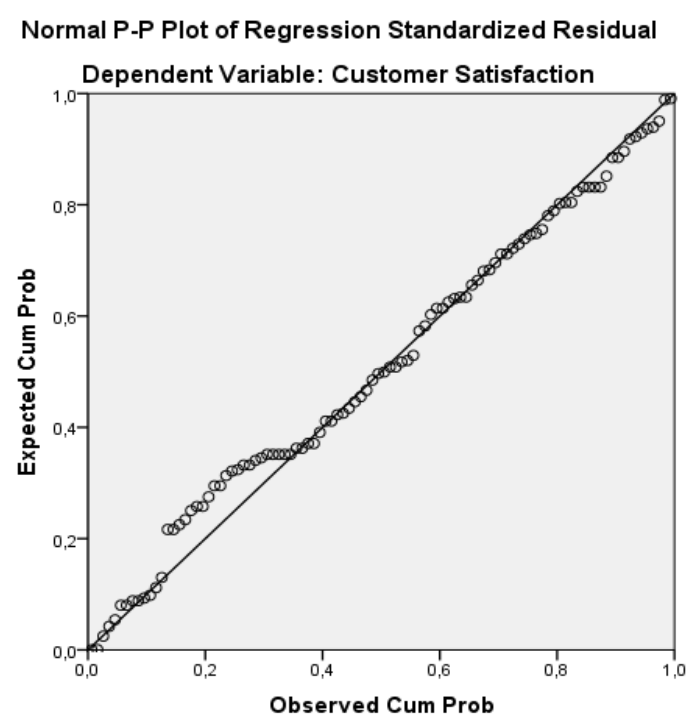




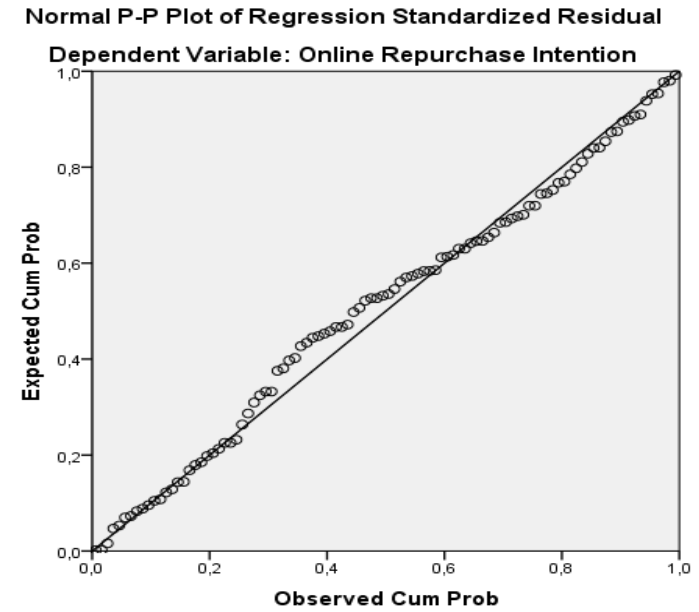

Gambar 5. Uji Normalitas Substruktural 2

Berdasarkan gambar diatas (Normal P-P Plot of Regression Standardized Residual) diketahui bahwa data menyebar disekitar garis diagonal. Maka model regresi tersebut memenuhi asumsi normalitas.

\section{Uji Hipotesis}

\section{Uji Hipotesis Parsial (Uji t)}

Tabel 9

Hasil Uji Parsial (Uji t) Substruktural 1 Coefficients $^{\mathrm{a}}$

\begin{tabular}{|c|c|c|c|c|}
\hline \multirow{3}{*}{ Model } & \multicolumn{4}{|l|}{ Standardized } \\
\hline & Coefficients & & $\mathrm{t}$ & Sig. \\
\hline & Std. Error & Beta & & \\
\hline (Constant) & ,904 & & $\begin{array}{l}-, 083 \\
\end{array}$ & ,934 \\
\hline $\mathrm{X} 1$ & 063 & ,410 & 4,517 & 000 \\
\hline $\mathrm{X} 2$ & ,047 &, 384 & 4,238 & ,000 \\
\hline
\end{tabular}

Dependent Variable: Y1

\section{Tabel 10}

Hasil Uji Parsial (Uji t) Substruktural 2

\begin{tabular}{lccccc}
\hline \multirow{3}{*}{ Model } & \multicolumn{5}{c}{ Standardized } \\
& Coefficients & $\mathrm{t}$ & Sig. \\
\cline { 2 - 6 } & $\mathrm{B}$ & $\begin{array}{c}\text { Std. } \\
\text { Error }\end{array}$ & Beta \\
\hline (Constant) &, 989 &, 893 & & 1,108 &, 271 \\
X1 &, 195 &, 069 &, 239 & 2,841 &, 005 \\
X2 &, 173 &, 050 &, 285 & 3,424 &, 001 \\
\hline
\end{tabular}

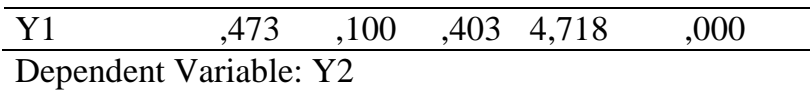

Berdasarkan tabel 9 dan 10, maka dapat dilihat hasil uji t yang menunjukkan hasil pengaruh tiap variabel dalam penelitian ini adalah sebagai berikut:

Tabel 11

Hasil Pengaruh Variabel

\begin{tabular}{clllll}
\hline No. & Hipotesis & Variabel & $\mathrm{t}_{\text {hitung }}$ & $\mathrm{t}_{\text {tabel }}$ & $\begin{array}{l}\text { Konseptu } \\
\text { al }\end{array}$ \\
\hline 1. & $\mathrm{H} 1$ & $\mathrm{X} 1 \longrightarrow \mathrm{Y} 1$ & 4,517 & 1,985 & Support \\
2. & $\mathrm{H} 2$ & $\mathrm{X} 2 \longrightarrow \mathrm{Y} 1$ & 4,328 & 1,985 & Support \\
3. & $\mathrm{H} 3$ & $\mathrm{X} 1 \longrightarrow \mathrm{Y} 2$ & 2,841 & 1,985 & Support \\
4. & $\mathrm{H} 4$ & $\mathrm{X} 2 \longrightarrow \mathrm{Y} 2$ & 3,424 & 1,985 & Support \\
\hline
\end{tabular}

Koefisien Determinasi

Tabel 12

Hasil Uji Koefisien Determinasi Substruktural 1

Model Summary

\begin{tabular}{ccccc}
\hline Model & $\mathrm{R}$ & $\begin{array}{c}\mathrm{R} \\
\text { Square }\end{array}$ & $\begin{array}{c}\text { Adjusted } \\
\text { R Square }\end{array}$ & $\begin{array}{c}\text { Std. Error of } \\
\text { the Estimate }\end{array}$ \\
\hline 1 &, $715^{\mathrm{a}}$ &, 512 &, 501 & 1,06403 \\
\hline
\end{tabular}

a. Predictors: (Constant), E-Service Quality, Customer Engagement

b. Dependent Variable: Customer Satisfaction

Berdasarkan tabel , hasil pengujian ini menunjukkan bahwa nilai Adjusted $R^{2}$ substruktural 1 sebesar 0,501 artinya sebesar $50,1 \%$ variabel customer satisfaction dapat dijelaskan oleh variabel customer engagement dan $e$ service quality, sedangkan sebesar 49,9\% $(100 \%$ - 50,1\%) dapat dijelaskan oleh variabel lain yang tidak ada dalam model penelitian ini. 
Tabel 13

Hasil Uji Koefisien Determinasi

Substruktural 2

Model Summary ${ }^{b}$

\begin{tabular}{llllc}
\hline Model & $\mathrm{R}$ & $\begin{array}{l}\mathrm{R} \\
\text { Square }\end{array}$ & $\begin{array}{l}\text { Adjusted } \\
\text { Square }\end{array}$ & $\begin{array}{c}\text { Std. } \\
\mathrm{R} \text { of } \\
\text { Estimate }\end{array}$ \\
\hline 1 &, $811^{\mathrm{a}}$ &, 657 &, 646 & 1,05108 \\
the
\end{tabular}

a. Predictors:(Constant),Customer Satisfaction, E-Service Quality, Customer Engagement

b. Dependent Variable: Online Repurchase Intention

Berdasarkan hasil tabel diatas, hasil pengujian menunjukkan bahwa nilai Adjusted $R^{2}$ substruktural 2 sebesar 0,646 artinya sebesar 64,6\% variabel customer satisfaction dapat dijelaskan oleh variabel customer engagement dan e-service quality, sedangkan sebesar 35,4\% (100\% - 64,6\%) dapat dijelaskan oleh variabel lain yang tidak ada dalam model penelitian ini.

\section{Analisis Korelasi}

Tabel IV-14

Hasil Analisis Korelasi Correlations

\begin{tabular}{llll}
\hline & & $\begin{array}{l}\text { Custom } \\
\text { er } \\
\text { Engage } \\
\text { ment }\end{array}$ & $\begin{array}{l}\text { E-Service } \\
\text { Quality }\end{array}$ \\
\hline $\begin{array}{lll}\text { Customer } \\
\text { Engageme }\end{array}$ & Pearson & 1,000 & 0,623 \\
$n t$ & Correlation & & \\
& Sig & 0,000 & 0,000 \\
E-Service & $\mathrm{N}$ & 100 & 100 \\
Quality & Pearson & 0,623 & 1,000 \\
& Correlation & & \\
& Sig & 0,000 & 0,000 \\
& $\mathrm{~N}$ & 100 & 100 \\
\hline
\end{tabular}

Berdasarkan tabel diatas dapat disimpulkan bahwa hubungan customer engagement dengan e-service quality memiliki nilai sebesar 0,623 sehingga dapat dikatakan memiliki korelasi kuat.

\section{Analisis Jalur}

Analisis jalur merupakan suatu metode penelitian yang utamanya digunakan untuk menguji kekuatan dari hubungan langsung dan tidak langsung di antara berbagai variabel.

\section{Koefisien Jalur}

Koefisien jalur menunjukkan kuatnya pengaruh variabel independen terhadap dependen. Koefisien jalur dapat dihitung dengan persamaan structural yang terdiri dari dua persamaan, dimana $\mathrm{X} 1, \mathrm{X} 2$ adalah variabel independen, Y1 dan Y2 adalah variabel dependen, yang dirumuskan sebagai berikut:

$$
\epsilon_{1}=\sqrt{ } 1-R^{2}=\sqrt{ } 1-0,512=0,698
$$

$Y 1=0,410 X 1+0,384 X 2+0,698$

Keterangan:

a. Koefisien regresi variabel customer engagement $(\mathrm{P} 1)=0,410$

Koefisien regresi untuk X1 sebesar 0,410 artinya setiap penambahan 1 satuan pada variabel customer engagement (X1), maka akan menambah customer satisfaction sebesar 0,410 .

b. Koefisien regresi variabel e-service quality $(\mathrm{P} 2)=0,384$

Koefisien regresi untuk X2 sebesar 0,384 artinya setiap penambahan 1 satuan pada variabel e-service quality (X2), maka akan menambah customer satisfaction sebesar 0,384 .

c. Nilai Residu $\left(€_{1}\right)=0,698$

Nilai residu yang sebesar 0,698 menunjukkan customer satisfaction yang tidak dapat dijelaskan oleh variabel customer engagement (X1), dan e-service quality (X2) diabaikan atau sama dengan 0 (nol).

$€_{2}=\sqrt{ } 1-R^{2}=\sqrt{ } 1-0,657=0,585$

$\mathrm{Y} 2=0,239 \mathrm{X} 1+0,285 \mathrm{X} 2+0,403 \mathrm{Y} 1+0,585$

Keterangan:

a. Koefisien regresi variabel customer engagement $(\mathrm{P} 1)=0,239$

Koefisien regresi untuk X1 sebesar 0,239 artinya setiap penambahan 1 satuan pada variabel customer engagement (X1), maka akan menambah online repurchase intention sebesar 0,239 .

b. Koefisien regresi variabel $e$-service quality $(\mathrm{P} 2)=$ 0,285

Koefisien regresi untuk X2 sebesar 0,285 artinya setiap penambahan 1 satuan pada variabel $e$ service quality (X2), maka akan menambah online repurchase intention sebesar 0,285. 


\section{Pengaruh Customer Engagement dan E-Service Quality Terhadap Online Repurchase Intention dengan Customer Satisfaction sebagai Variabel Intervening}

c. Koefisien regresi variabel customer satisfaction $(\mathrm{P} 3)=0,403$

Koefisien regresi untuk Y1 sebesar 0,403 artinya setiap penambahan 1 satuan pada variabel customer satisfaction (Y1), maka akan menambah online repurchase intention sebesar 0,403 .

d. Nilai Residu $\left(€_{2}\right)=0,585$

Nilai residu yang sebesar 0,585 menunjukkan online repurchase intention yang tidak dapat dijelaskan oleh variabel customer engagement (X1), dan e-service quality (X2) dan customer satisfaction (Y1), diabaikan atau sama dengan 0 (nol).

\section{Diagram Jalur}

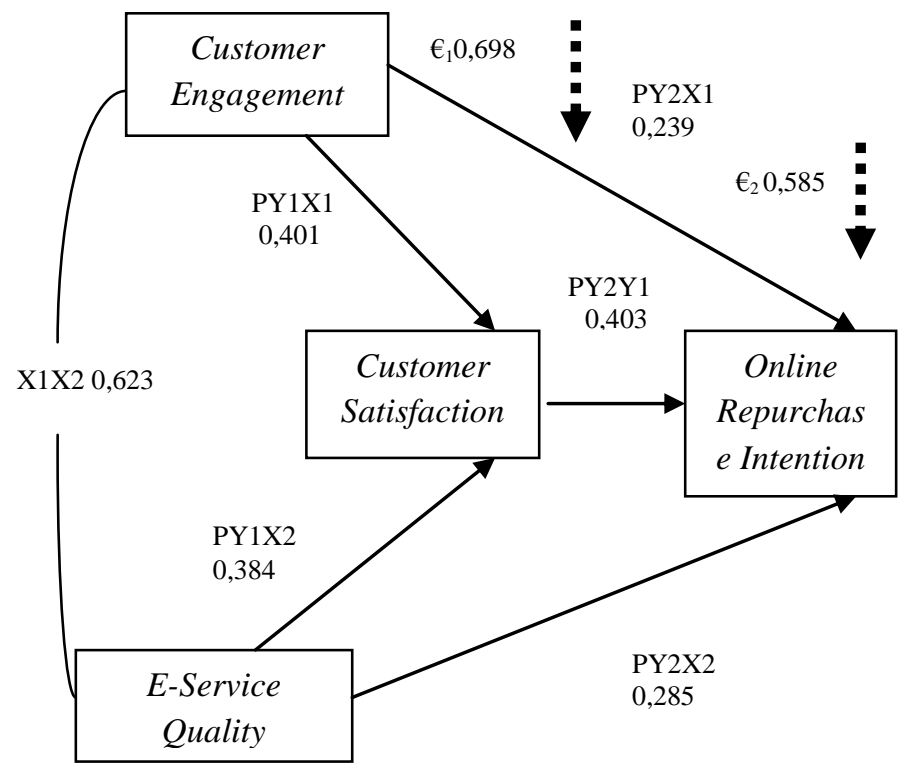

Berdasarkan gambar diagram analisis jalur diatas dapat dijelaskan

\section{Implikasi Manajerial}

Penelitian ini bertujuan untuk mengetahui seberapa besar pengaruh variabel customer engagement, dan e-service quality terhadap online repurchase intention dengan customer satisfaction sebagai variabel intervening pada mahasiswa STIE Putra Bangsa Kebumen yang pernah melakukan pembelian pada marketplace Shopee. Setelah dilakukan pengujian hipotesis, perlu dikembangkan implikasi manajerial sebagai berikut:

a. Pengaruh kuat customer engagement terhadap kepuasan pelanggan dan niat beli ulang online membuktikan tentang alasan pentingnya PT. Shopee untuk selalu fokus pada strategi pemasaran dan bertindak untuk cenderung mengengaged pelanggan dalam suatu interaksi atau bentuk komunikasi lainnya. Strategi yang diberlakukan oleh PT.Shopee dalam mengengaged customernya adalah melalui game-game shopee yang menarik, seperti: goyang shopee, kuis shopee, dan goyang hujan emas. PT.Shopee juga menciptakan media sosial sharing, agar lebih efektif dalam menciptakan keterikatan konsumen pada marketplace Shopee. Hal ini menimbulkan kepuasan tersendiri pada pelanggan, dan pada akhirnya mereka melakukan online repurchase intention pada marketplace Shopee.

b. E-Service Quality berpengaruh terhadap customer satisfaction dan online repurchase intention. PT.Shopee selama ini sudah memberikan pelayanan yang cukup baik terhadap customer, akan tetapi belum maksimal. Produsen PT.Shopee dalam memberikan pelayanannya kepada konsumen masih terdapat beberapa kekurangan, misalnya dalam memberikan respon live chat kepada pelanggan, masih cukup lambat, hal ini menjadikan konsumen merasa kecewa dengan $e$ service quality yang diberikan oleh marketplace Shopee, serta akan menjadikan pelanggan merasa kurang puas ketika berbelanja pada marketplace Shopee dan menjadikan pula mereka merasa kurang minat untuk melakukan online repurchase intention pada marketplace Shopee. 


\section{PENUTUP}

\section{Kesimpulan}

1. Customer engagement berpengaruh positif dan signifikan terhadap customer satisfaction pada mahasiswa STIE Putra Bangsa Kebumen yang pernah melakukan pembelian pada marketplace Shopee. Customer engagement mempunyai pengaruh yang lebih kuat terhadap customer satisfaction dibandingkan dengan e-service quality. Hal ini mencerminkan bahwa customer merasa lebih senang dan puas dengan fasilitas engaged yang diciptakan oleh pihak Shopee, yaitu melalui game-game shopee yang menarik, seperti goyang shopee, kuis shopee, goyang hujan emas, serta fasilitas media Sharing dan live chat daripada dengan $e$-service quality yang telah diberikan oleh marketplace Shopee kepada customer. Artinya bahwa semakin pelanggan engaged dengan marketplace Shopee, maka semakin tinggi pula tingkat kepuasan (customer satisfaction) pelanggan pada marketplace Shopee.

2. E-service quality berpengaruh positif dan signifikan terhadap customer satisfaction pada mahasiswa STIE Putra Bangsa Kebumen yang pernah melakukan pembelian pada marketplace Shopee. Namun pengaruhnya rendah, Hal ini dikarenakan e-service quality pada marketplace Shopee belum maksimal dalam memberikan pelayanan pada pelanggan sehingga tingkat kepuasan pelanggan rendah.

3. Customer engagement berpengaruh positif dan signifikan terhadap online repurchase intention pada mahasiswa STIE Putra Bangsa Kebumen yang pernah melakukan pembelian pada marketplace Shopee. Hal ini dapat diartikan bahwa semakin tinggi customer engagement maka akan semakin meningkatkan online repurchase intention.

4. E-service quality berpengaruh positif dan signifikan terhadap online repurchase intention pada mahasiswa STIE Putra Bangsa Kebumen yang pernah melakukan pembelian pada marketplace Shopee. Hal ini dapat diartikan bahwa semakin tinggi e-service quality maka akan semakin meningkatkan online repurchase intention.

5. Customer satisfaction berpengaruh positif dan signifikan terhadap online repurchase intention pada mahasiswa STIE Putra Bangsa Kebumen yang pernah melakukan pembelian pada marketplace Shopee, namun berdasarkan hasil penelitian yang dilakukan bahwa setelah variabel customer engagement dan e-service quality di intervening dengan customer satisfaction, pengaruhnya menjadi kecil terhadap variabel online repurchase intention. Hal ini dapat diartikan bahwa variabel intervening customer satisfaction kurang kuat dalam mempengaruhi online repurchase intention dalam penelitian ini.

\section{Saran}

1. Pihak PT. Shopee Internasional Indonesia

a. E-Service qualiy yang selama ini diberikan oleh pihak Shopee mempengaruhi customer satisfaction dan online repurchase intention, namun pengaruhnnya rendah, hal ini dikarenakan Shopee kurang maksimal dalam memberikan pelayanannya kepada customer terutama dalam hal respon live chat yang cukup lama,sehingga menyebabkan konsumen kurang puas terhadap marketplace Shopee, dalam hal ini penulis menyarankan kepada Shopee untuk memberikan respon live chat yang cepat kepada pelanggannya, misalkan dengan menciptakan layanan audiovisual, agar dapat merespon pelanggan secara langsung dan lebih efektif, atau dengan menerapkan kebijakan seperti reward and punishment kepada produsen agar mereka lebih giat dalam menerapkan pelayanan yang baik dan lebih memuaskan kepada pelanggannya, melalui penilaian yang diberikan oleh pelanggan saat melakukan pembelian pada marketplace Shopee, misalnya bagi produsen yang mendapatkan penilaian baik oleh pelanggan akan mendapatkan hadiah sejumlah uang, sedangkan bagi produsen yang mendapat penilaian yang buruk dari pelanggan, maka mereka akan mendapat hukuman. Hukuman yang dapat diberlakukan oleh PT.Shopee misalnya, dengan me-non aktifkan akun produsen secara otomatis selama 24 jam, dengan demikian para produsen akan berlomba-lomba untuk memberikan pelayanan yang terbaik kepada pelanggannya.

b. Customer engagement mempunyai pengaruh yang cukup kuat terhadap customer satisfaction dan online repurchase intention, oleh karena itu penulis menyarankan sebaiknya pihak Shopee harus tetap konsisten mempertahankan game shopee nya 
dan terus berinovasi dalam menciptakan game-game Shopee terbaru agar meningkatkan keterikatan konsumen serta agar konsumen selalu menggunakan aplikasi Shopee sebagai pilihan utamanya dalam berbelanja online, dikarenakan konsumen merasa puas dan pada akhirnya, mereka akan melakukan online repurchase intention, serta kepada pihak Shopee agar selalu membangun interaksi yang baik kepada para pelanggan melaui aktivitas sharing melalui media sosial dengan meninjau ulang konten-konten digital yang digunakan. Hal ini bertujuan supaya PT.Shopee tidak hanya sekedar memotivasi pelanggan untuk berinteraksi saja, tetapi mampu mempengaruhi pelanggan agar melakukan pembelian secara berulang pada marketplace Shopee.

c. Customer satisfaction mempengaruhi online repurchase intention, oleh karena itu penulis menyarankan sebaiknya pihak Shopee harus tetap mempertahankan strateginya dalam meningkatkan kepuasan konsumen, melalui aktivitas engaged yang diciptakan Shopee seperti selalu berinovasi menciptkan game Shopee yang lebih menarik, atau dengan mengadakan undian Shopee agar konsumen merasa senang dengan aplikasi Shopee dan kemudian menyebabkan mereka puas berbelanja di aplikasi Shopee, sehingga akan mendorong mereka untuk berniat melakukan pembelian ulang.

2. Bagi Peneliti Selanjutnya

Peneliti selanjutnya diharapkan dapat menambahkan atau mengganti salah satu variabel independen, misalnya dengan variabel customer involvement, shopping experience, atau fenomena goyang Shopee, agar lebih menarik.

Dalam penelitian ini variabel customer engagement dan e-service quality setelah di intervening oleh variabel customer satisfaction pengaruhnya menjadi kecil terhadap online repurchase intention oleh karena itu penulis menyarankan bagi peneliti selanjutnya agar mengganti variabel interveningnya dengan variabel lain, misalnya dengan menggunakan variabel Trust (kepercayaan).

Kemudian penelitian selanjutnya juga dapat mengganti indikator-indikator yang lebih relevan dengan penelitian sehingga dapat memperoleh hasil penelitian yang diharapkan dan lebih mendekati kebenarannya. Selain itu, penelitian selanjutnya juga dapat menggunakan subjek penelitian yang berbeda dan memperbanyak jumlah responden yang diteliti.
3. Keterbatasan Penelitian

Penelitian yang dilaksanakan ini mempunyai keterbatasan, oleh karena itu keterbatasan ini perlu diperhatikan untuk peneliti-peneliti selanjutnya, keterbatasan tersebut adalah sebagai berikut:

a. Penelitian ini dilakukan pada mahasiswa STIE Putra Bangsa Kebumen, apabila penelitian ini dilakukan kembali pada objek yang berbeda kemungkinan hasil dalam penelitian akan berbeda.

b. Penelitian ini terbatas pada variabel customer engagement, e-service quality, customer satisfaction, dan online repurchase intention.

\section{DAFTAR PUSTAKA}

Anderson, R.E. dan Srinivasan, S.S. 2003. E-Satisfaction and E-Loyalty: A Contingensi Framework. Psychology \& Marketing. Vol.20, No. 2,123-135.

Arifin,S. dan Saidani.B. 2012. Pengaruh Kualitas Produk dan Kualitas Layanan Terhadap Kepuasan Konsumen dan Minat Beli Ulang pada Ranch Market.Jurnal Riset Manajemen Sains Indonesia (JRMSI).Vol.3, No. 1.

Dian, Ristina.A dan Rusfian, Effy.Z. 2013. Pengaruh E-Service Quality Terhadap Repurchase Intention Melalui Customer Satisfaction. Jurnal Administrasi Niaga. Jakarta: FISI UI.

Ghada. A dan Roushdy. 2017. The Impact of Customer Engagemet On Repurchase Intention A mediating Role Customer satisfaction.

Gozali, Imam. 2001. Aplikasi Analisis Multivariat dengan Program SPSS. Cetakan IV. Semarang Universitas Diponegoro.

. 2009. Aplikasi Analisis Multivariate dengan Program IBM SPSS 20. Semarang: Badan Penerbit Universitas Diponegoro.

Paramitha, Amelia. 2018. Pengaruh EService Quality Terhadap Keputusan Konsumen Dalam Melakukan Transaksi Melalui E-Commerce Serta 
Pengaruh Customer Engagement dan E-Service Quality Terhadap Online Repurchase Intention dengan Customer Satisfaction sebagai Variabel Intervening

Dampaknya Pada Kepuasan Konsumen. E journal Administrasi Bisnis. ISSN 2355-5408. Vol.6.No.3.

Rahmawati, E.S. 2015. Pengaruh Customer Engagement Terhadap Kepuasan Pelanggan dan Kepercayaan Merek Serta Dampaknya Pada Loyalitas Merek. Jurnal Riset Ekonomi dan Manajement. Vol.15.No.2,246-21.

Sarwono. 2005. Teori dan Praktik Riset Pemasaran dengan SPSS. Yogyakarta: ANDI OFFEST.

Subagiyo, Rochmat dan Adlan, Aqim. M. 2007. Pengaruh Service Quality, Marketing Mix dan Kepuasan Mahasiswa Terhadap Customer Loyalty. Jurnal Ekonomi Modernisasi. 13(1), 1-15.

Taufan, Bimo, Yianto.E, dan Kumadji.S. 2016. Pengaruh E-Service Quality dan Perceived Velue Terhadap Kepuasan
Pelanggan dan Loyalitas Pelanggan. Jurnal Administrasi Bisnis (JAB).Vol 38.No. 2.

Tjiptono, Fandy. 2007. Strategi Pemasaran. Edisi kedua. Andi: Yogyakarta.

http://www.apjii.or.id diakses tanggal 19

Oktober 2018

https://id.techinasia.com/penetrasi-internet-

di-indonesia-2017 diakses tanggal

21 Oktober 2018

https://katadata.co.id/berita/2018/03/02/shop ee-cetakan-transaksi-rp-59-triliun-

40-dari-indonesia diakses tanggal 2

November 2018

www.shopee.co.id diakses tanggal 4

November 2018 